\title{
Computer maintenance service: Tymshare, Inc.
}

\author{
ISAAC CABASE, JR. \\ Tymshare, Inc., Cupertino, California 95014
}

A computer maintenance service provided by Tymshare, Inc., is described.

Tymshare is an international service organization whose expertise is providing computer up-time and effectively applying the computer to the access, analysis, and use of information. Of chief importance, we are a single organization able to assist in any phase of computerized information management, problem solving, maintenance, and equipment upgrades.

Third-party maintenance was formed within Tymshare because of the need to keep our in-house data processing systems operating more efficiently. Since then this service has been expanded and has been offered to outside organizations.

Tymshare has made long-term commitments to support its customers through a "total service" concept. Service is our only business. Our heavily experienced people are available and geared to the total support of computer systems such as those manufactured by the following companies: Digital Equipment Corporation (DEC-PDP), Xerox Data Systems (XDS) Sigma Series, and Lockheed Systems (System III).

Support is also available to vendors who provide add-on equipment to the systems outlined above and

Tymshare, Inc., Equipment Support Division, computer maintenance is located at 10231 Bubb Road, Cupertino, California 95014, phone: (408) 446-6000. also on the IBM 370 and $330 \mathrm{X}$ systems such as Intel, Telefile, Mostek, Ampex, Storage Technology, Memorex, Control Data, Plessey, Pertec, Western Peripherals, Kennedy, Able Computer, Data Products, Data Printer, Printronix, Versatec, and more.

The advantages offered are many. Some of these are: single-source maintenance, financially solvent organization, and large inventory of parts. In addition, we can also provide: additional hardware components and/or full systems, system upgrades, system staging facilities, and component, unit, or full-system refurbishment.

Tymshare computer maintenance (TCM) customers have found that they can count on excellent service, personal attention, and reduced costs. A partial list of these customers includes: the nuclear energy technical community, such as the Department of Energy, General Atomic; government agencies, such as the Department of Commerce, U.S. Army, Navy, the Department of Energy; and universities, such as the University of Chicago, Cal-Tech, Princeton University, Georgetown University.

Organizations and individuals should consider thirdparty maintenance as a viable alternative to the original manufacturers' services. At Tymshare, we are prepared to offer you these services today and stand by you for the tomorrows to come. 